\title{
DEVELOPMENT, EVALUATION AND CHARACTERISTICS OF OPHTHALMIC IN SITU GEL SYSTEM: A REVIEW
}

\author{
MRINMOY DEKA*, ABDUL BAQUEE AHMED, JASHOBIR CHAKRABORTY \\ Girijananda Chowdhury Institute of Pharmaceutical Science (GIPS), Hatkhowapara, Azara, Guwahati 781017 Assam \\ Email: mrinmoyprincedeka@gmail.com
}

Received: 20 Apr 2019, Revised and Accepted: 26 Jun 2019

\begin{abstract}
Eye is a sensitive organ and is easily injured and infected. Delivery of drugs into eye is complicated due to removal mechanism of precorneal area results decrease in therapeutic response. Conventional ocular delivery systems like solution, suspension, ointment shows some disadvantages such as rapid corneal elimination, repeated instillation of drug and short duration of action. In situ polymeric delivery system will help to achieve optimal concentration of drug at the target site, thereby helps to achieve the desired therapeutic concentration. There are various novel ocular drug delivery systems such as In-situ gel, dendrimers, niosomes, nanoparticulate system, collagen shield, ocular iontophoresis suspension and ocusert etc. In situ gelling systems are liquid upon instillation and undergo a phase transition to form gel due to some stimuli responses such as temperature modulation, change in $\mathrm{pH}$ and presence of ions. Various attempts have been made towards the development of stable sustained release in-situ gels. Newer research in ophthalmic drug delivery systems is directed towards an incorporation of several drug delivery technologies, that includes to build up systems which is not only extend the contact time of the vehicle at the ocular surface, but which at the same time slow down the removal of the drug. This is a review based on ocular in situ gels, characteristization, techniques and evaluation of in situ ophthalmic drug delivery systems,
\end{abstract}

Keywords: In-situ gel, Novel ocular delivery, Phase transition, Temperature, pH triggered

(C) 2019 The Authors. Published by Innovare Academic Sciences Pvt Ltd. This is an open access article under the CC BY license (http://creativecommons.org/licenses/by/4.0/) DOI: http://dx.doi.org/10.22159/ijcpr.2019v11i4.34949

\section{INTRODUCTION}

The ocular drug delivery system is considered as most crucial and challenging as human eye is an isolated organ where the delivery of drug is quite difficult. Moreover, the conventional ophthalmic formulations unveil a short pre-corneal residence time and poor bioavailability due to rapid and extensive elimination of drugs from pre-corneal lachrymal fluid by solution drainage, lachrymation, and non-productive absorption by conjunctiva [1]. In order to surpass the drawbacks associated with the conventional ophthalmic formulations, various attempts have been made towards the development of stable sustained release in-situ gels. Newer research in ophthalmic drug delivery systems is directed towards an incorporation of several drug delivery technologies, that includes to build up systems which is not only extend the contact time of the vehicle at the ocular surface, but which at the same time slow down the removal of the drug. In situ gel system is formulated as liquid preparation suitable to be instilled into eyes which upon exposure to the physiologic environment changes to gel results in in-situ gel, thus increasing the precorneal residence time of the delivery system, and enhances the ocular bioavailability of the drug [2]. The formation of gels depends on factors like change in a specific physico-chemical parameter $(\mathrm{pH}$, temperature, ion-sensitive) by which the drug gets released in a sustained and controlled manner. These systems were evaluated for drug content, clarity, $\mathrm{pH}$, gelling capacity, viscosity, in vitro drug release studies, texture analysis, sterility testing, isotonicity evaluation, accelerated studies and irritancy test. FT-IR spectroscopy was used to know drug and polymer incompatibilities [3]. There are various new dosage forms like in situ gel, collagen shield, minidisc, ocular film, ocusert, nanosuspension, nanoparticulate system, liposomes, niosomes, dendrimers, ocular iontophoresis etc.

Smart polymeric systems have proved to be promising means of delivering the drugs. These polymers undergo sol-gel transition after administered. They are in solution phase before administration, but gels under physiological condition. The ocular bioavailability of the drugs can be improved by prolonging their residence time in the cul-de-sac and by increasing their corneal permeability [5]. There are various physical and chemical stimuli leading to in situ gel formation viz. temperature, $\mathrm{pH}$, electric field, magnetic field and light. Stimuli responsive polymer mimics biological system in a crude way where an external stimulus $\mathrm{pH}$ and temperature) result in a change in the properties of the formulation. Both natural and synthetic polymers can be used for the production of in situ gels. So, in situ gels are administered by oral, ocular, rectal, vaginal, injectable and intra-peritoneal routes [6].

This review demonstrates a brief summary about in situ gels, various approaches for in situ gelling systems. Also different types of smart polymers, their mechanisms of gel formation from the sol forms and evaluation of polymeric in situ gel. The main objective of in situ gelling system is to attain the proposed quantity of drug in eye. This is the challenging thing which is overcome by new technology over conventional dosage form.

The various problem associated with poor bioavailability of ocular delivery are-Drainage of instilled solution. Binding by lachrymal proteins. Tear turn over. Limited corneal area and poor corneal metabolism. Non-product absorption.

To overcome these limitations, researchers had developed novel dosage form in ocular drug delivery. The main objective of the improvement is to maintain the drug in the eye cavity for a longer period of time. Successful results have been obtained especially in geriatric patients with collagen shields and inserts, in spite of disadvantages like poor patient compliance and losing the device without noticing it.

These are the six main properties of ophthalmic preparations: Sterility, Preservation, Particle Limitations, pH, Stability, and Eye comfort. The main requirement is sterility, it is very important to make sure that medications applied to the eye should be sterile. If there are any abrasions in the eye, it is very easy for microorganisms to penetrate that area and cause an eye infection. Infection of Pseudomonas aeruginosa can lead to rapid onset of blindness (2-3 d) as a result of exposure to contaminated ophthalmics. It is possible to sterilize products using either autoclaving (for heat stable drugs) or membrane filtration with a 0.22 micrometer filter (for heat-labile drugs). Membrane filtration is very effective because it sterilizes the solution as well as removes particulate matter. Tear fluid is isotonic with blood and other tissues, so the drug solutions need to be isotonic to reduce tearing and irritation. Irritation of the eye leads to increased tearing which washes away the drug and leads to less being absorbed. $0.9 \%$ sodium chloride and $1.9 \%$ boric acid are isotonic with the tears. Typically, the eye can tolerate solutions with tonicity values ranging from equivalents of $0.5 \%$ to $1.6 \%$ 
sodium chloride without discomfort. There are even some therapeutic drug concentrations that are hypertonic, but they are applied in such small amounts that the eye can tolerate them. Antioxidants, chelating agents, and surfactants are all used to stabilize ophthalmic products. Lastly adjuvants are added to provide lubrication and protection against drying and cracking. Emollients provide oil to the tears to prevent them from evaporating. This is particularly important in patients with dry eyes. Demulcents have the ability to hold water and keep the membranes of the eyes in a hydrated form. All of these properties of ophthalmic are very important to the sterility, stability, and comfort of the product once applied to the eye.

\section{Advantages of in situ ocular drug delivery systems}

To provide sustained and controlled drug delivery. To increase the ocular bioavailability of drug by increasing the corneal contact time.
Drug effect is prolonged hence frequent instillation of drug is not required. For patient compliance and enhance therapeutic performance of drug.

Generally more comfortable than insoluble or soluble insertion. System provides ease of administration [7].

Ideal characteristics of polymers for preparation of in situ ophthalmic

Gels

It should be biocompatible. It is capable of adhering to the mucus membrane. Preferred pseudo plastic behavior of polymer. Good tolerance and optical clarity is more preferred. It should influence the tear behavior. The polymer should be capable of decreasing the viscosity with increasing shear rate [8].

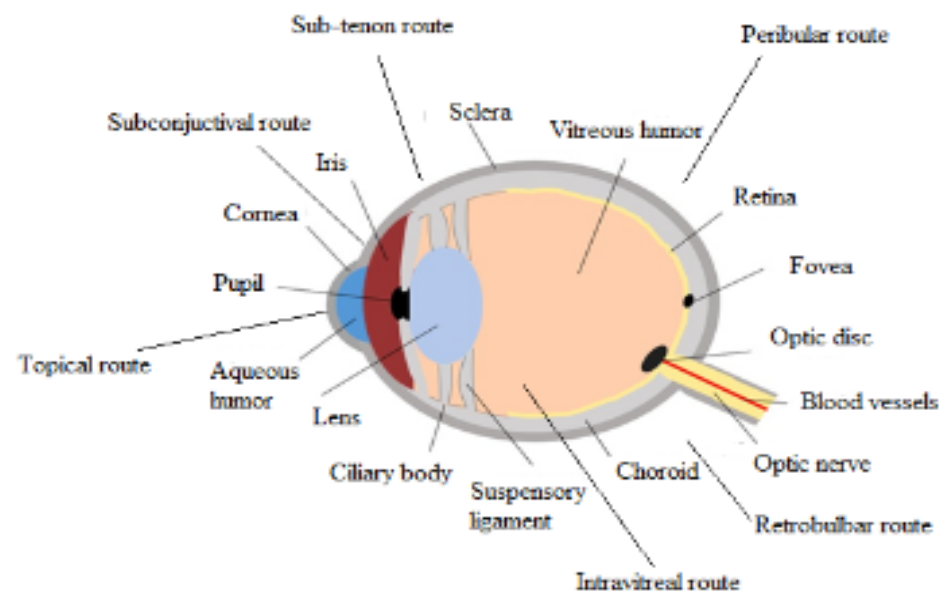

Fig. 1: Structure and schematic representation of various routes of ocular drug delivery

\begin{abstract}
Anatomy of eye
An eye is a spherical structure with a wall made up of three layers: the outer part sclera, the middle parts choroid layer, ciliary body and iris and the inner section nervous tissue layer retina. The sclera is tough fibrous coating that protecting the inner tissues of eye which is white except for the transparent area at the front, that is cornea allows light to enter to the eye. The choroid layer, situated in the sclera, contains many blood vessels that modified at front of the eye as pigmented iris the colored part of the eye (blue, green, brown, hazel, or grey).
\end{abstract}

The front part of the eye (the part you see in the mirror) includes: The iris, cornea, pupil, sclera, conjunctiva.

Just behind the iris and pupil lies the lens, which helps to focus light on the back of the eye. $80 \%$ of the eye is filled with a clear gel called as vitreous. Light passes through the pupil and the lens then it will reaches back of the eye. The inner part of the eye is protected by special lightsensing cells are together known as retina. The retina transforms light into electrical impulses. Behind the eye, the optic nerve conveys these impulses to the brain. The macula is a small extra-sensitive area which is present in retina that gives central vision. This is located in the center of the retina and contains the fovea, a small depression or pit at the middle of the macula that gives the clear vision [9-12].

\section{Eye conditions}

\section{Amblyopia (lazy eye)}

One eye sees better than the other as a result of not using the other eye during childhood. The weaker eye may or may not "wander." The weaker eye is called the "lazy eye."

\section{Astigmatism}

A defect that causes an inability to properly focus light onto the retina. Astigmatism causes blurry vision that can be corrected with glasses, contact lenses, or, in some cases, surgery.

\section{Black eye}

Swelling and discoloration (bruise) around the eye as a result of injury to the face.

\section{Blepharitis}

Inflammation of the eyelids near the eyelashes. Blepharitis is a common cause of itching or a feeling of grit in the eyes.

\section{Cataract}

A clouding of the natural internal lens of the eye, which can cause blurred vision.

\section{Chalazion}

An oil-making gland gets blocked and swells into a bump.

\section{Conjunctivitis}

Also known as "pinkeye," conjunctivitis is an infection or inflammation of the conjunctiva, the clear layer that covers the front of the eye. It is usually caused by allergies, a virus, or a bacterial infection.

\section{Corneal abrasion}

A scratch on the clear part of the front of the eye. Pain, light sensitivity, or a feeling of grit in the eye is the usual symptoms.

\section{Diabetic retinopathy}

High blood sugar damages blood vessels in the eye. Eventually, weakened blood vessels may start leaking or overgrow the retina, threatening vision.

\section{Diplopia (double vision)}

Seeing double can be caused by many serious conditions. Diplopia requires immediate medical attention. 


\section{Dry eye}

Either the eyes don't produce enough tears, or the tears are of poor quality. Dry eye can be caused by medical problems such as lupus, scleroderma, and Sjogren's syndrome.

\section{Glaucoma}

Progressive loss of vision usually associated with increased pressure inside the eye. Peripheral vision is lost first, often going undetected for years.

\section{Hyperopia (farsightedness)}

Inability to see near objects clearly. The eye is "too short" for the lens, or certain eye muscles have weakened with age.

Keratitis: Inflammation or infection of the cornea. Keratitis typically occurs after germs enter a corneal abrasion.

\section{Myopia (nearsightedness)}

Inability to see clearly at a distance. The eye is "too long" for the lens, so light isn't focused properly on the retina.

\section{Optic neuritis}

The optic nerve becomes inflamed, usually from an overactive immune system. Painful vision loss in one eye typically results.

\section{Pterygium}

A thickened conjunctival mass usually on the inner part of the eyeball. It may cover a part of the cornea, causing vision problems.

\section{Retinal detachment}

The retina comes loose from the back of the eye. Trauma and diabetes are common causes of this problem, which often requires urgent surgical repair.

\section{Retinitis}

Inflammation or infection of the retina. Retinitis may be a long-term genetic condition or result from an infection.

\section{Scotoma}

A blind or dark spot in the visual field.

\section{Strabismus}

The eyes do not point in the same direction. The brain may then favor one eye, causing decreased vision (amblyopia) in the other eye.

\section{Stye}

Bacteria infect the skin on the edge of the eyelid, creating a tender red bump.

\section{Uveitis (iritis)}

The colored part of the eye becomes inflamed or infected. An overactive immune system, bacteria, or viruses can be responsible.

\section{Types of conventional dosage forms}

\section{Solutions}

Ophthalmic solutions are sterile, isotonic, which may be aqueous or oily preparation including emulsion and suspension of one or more active ingredients meant for instill into the eye, were the drug will absorbed or adsorbed into the eye to produce intended action. They may contain recipients which regulate osmotic pressure, $\mathrm{pH}$, and viscosity of the preparations, some times which may or may not use preservative also.

\section{ointment}

These are semisolid dosage forms which are meant for external use, generally it contains solid or semisolid hydrocarbon base of melting or softening point which resembles to human body temperature. After applying the ointment to the eye, it will converts into small drops, which remains for a long duration of time in conjunctival sac, thus increasing drug's bioavailability. Eye ointments have few disadvantages such as blurring of vision and sometimes have irritating effects in eye, because of which they are mainly applied night-time, although they are safe and well tolerated.

\section{Gels}

Gel formation is an extreme case of viscosity enhancement through the use of viscosity enhancers. Instead of giving multiple doses in case of solutions the dosing interval can be reduced in case of gels. Cellulose acetate phthalate dispersion constituted a microreservoir system of high viscosity. Poloxamer 407 is used as an ophthalmic vehicle for pilocarpine delivery and found that the gel formation enhances the activity of pilocarpine. Timolol maleate form thermogellingdrug delivery system composed of cellulose ether ethyl hydroxylethylcellulose. The effect of Flurbiprofen, which is a NSAID, formulated in Pluronic F-127 and carbopol 940. Gelrite is a polysaccharide which is also known as gellan gum. It forms a clear gel in the presence of mono or divalent cations. The high viscosity of the gel, however, results in blurred vision and malted eyelids which substantially decreases patient acceptability. Sterilization is another drawback for large scale production. As the conventional dosage forms are less bioavailable in case of ocular preparations the newer trend has comei.e., Ophthalmic gels. This review attempts to discuss the various approaches, mechanisms and evaluations of ocular preparations.

\section{In-situ ophthalmic gel system}

This is a system were the formulation behave like solution form, which changes the behavior to gel when it is instilled into the eye. Few mechanisms proposed are:

\section{In-situ gel formation based on physical mechanism}

\section{Swelling}

In-situ formation may also occur when material absorbs water from surrounding environment and expand to occupy desired space. Substance like glycerol which is polar polymerizable rapidly undergo photo-polymerisation in the presence of suitable photo initiator. Generally, long wavelength ultraviolet and visible wavelengths are used. Short wavelength ultraviolet is not used often because it has limited penetration of tissue and biologically harmful. A ketone, such as 2, 2 dimethoxy-2-phenyl acetophenone, is used as the initiator for ultraviolet photo-polymerization, whereas camphor quinone and ethyl eosin initiators are used in visible light systems. These systems can be designed for degradation by chemical or enzymatic processes or can be designed for long term persistence in vivo Photopolymerizable systems. When it is introduced to the desired site via injection it gets photocured in-situ with the help of fiber optic cables and then releases the drug for prolonged period of time. The photo-reactions provide rapid polymerization rates at physiological temperature. Further, the systems are formed in complex shaped volumes leading to an implant formation. A photopolymerizable, biodegradable hydrogel is a tissue contacting material and controlled release carrier.

\section{Diffusion}

This method involves the diffusion of solvent from polymer solution into surrounding tissue and results in precipitation or solidification of polymer matrix. $\mathrm{N}$-methyl pyrrolidone (NMP) has been shown to be useful solvent for such system $[13,14]$.

\section{In-situ formation based on chemical reactions}

Chemical reactions that results in-situ formation involves precipitation of inorganic solids from supersaturated ionic solutions, enzymatic processes, and photo-initiated processes.

\section{Ionic cross linking}

In Ionic cross linking polymer undergo phase transition in different ions due to this gels are formed. Mostly the polysaccharides are from the ion-sensitive ones, i-carrageenan forms elastic gels mainly in the presence of $\mathrm{Ca} 2$ +and $\mathrm{K}$-carrageen forms brittle and rigid gels in presence of small amount of $\mathrm{K}+$. Gellan gum is a polymer which expressed in the name of Gelrite is an anionic polysaccharide which 
is widely used, that undergoes in-situ gelling in the presence of mono-and divalent cations, including $\mathrm{K}+, \mathrm{Ca} 2+$, a $\mathrm{Na}+$ and $\mathrm{Mg} 2+$, Gelation of the low-methoxypectins can be caused by divalent cations, especially $\mathrm{Ca} 2+$. Likewise, alginic acid undergoes gelation in presence of divalent/polyvalent cations e+-g. Ca2+due to the interaction with glucoronic acid block in alginate chains.

\section{Enzymatic cross-linking}

In case of enzymatic cross linking mostly gels are formed by chemical and photochemical and it may also forms by catalytical reactions, even though $I n$-situ formation catalysed by natural enzymes has not been investigated widely but seems to have some advantages over chemical and photochemical approaches. For example, an enzymatic process operates efficiently under physiologic conditions without need for potentially harmful chemicals such as monomers and initiators. Intelligent stimuli-responsive delivery systems using hydrogels that can release insulin have been investigated. Adjusting the amount of enzyme also provides a convenient mechanism for controlling the rate of gel formation, which allows the mixtures to be injected before gel formation.

\section{Approaches in in-situ gel drug delivery}

pH sensitive in situ gelling system. Temperature sensitive in situ gelling system. Ion sensitive in situ gelling system.

\section{pH sensitive in situ gelling system}

In this system, gelling of the solution is triggered by change in $\mathrm{pH}$, when $\mathrm{pH}$ is raised from 5-7.412. At higher $\mathrm{pH}$, polymer forms hydrogen bond with mucin, which leads to hydrogel formation.

\section{Example}

Cellulose acetate phthalate, Polyacrylic acid (Carbopol), Polycarbophils, Polyethylene Glycol are $\mathrm{pH}$ dependent polymers

\section{Mechanism for $\mathrm{pH}$ sensitive gelling system}

All pH sensitive polymers contain pendant acidic or basic groups that can either accept or release protons in response to changes in environmental $\mathrm{pH}$. In case of weakly acidic group, swelling of hydrogel increases as the external $\mathrm{pH}$ increases, while decreases in case of weakly basic groups [15].
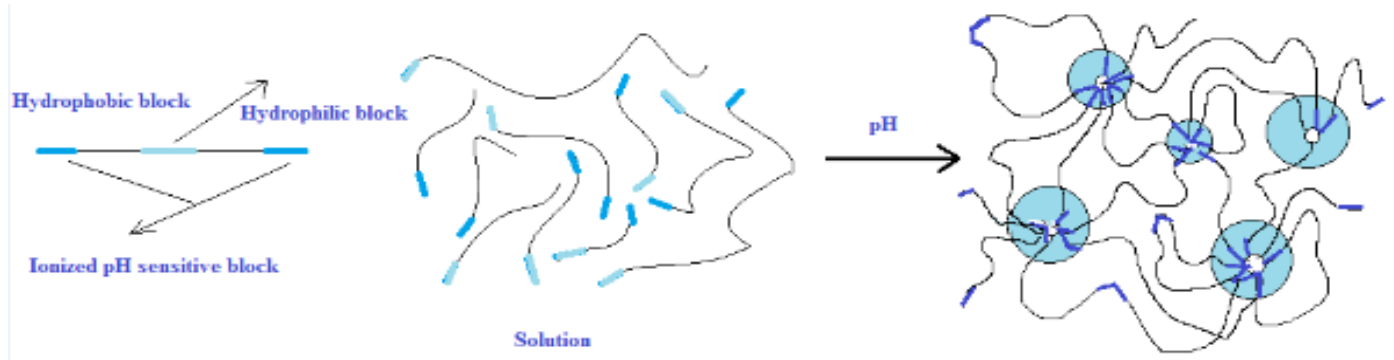

Gel

Fig. 2: Mechanism of $\mathrm{pH}$ sensitive in situ gelling system

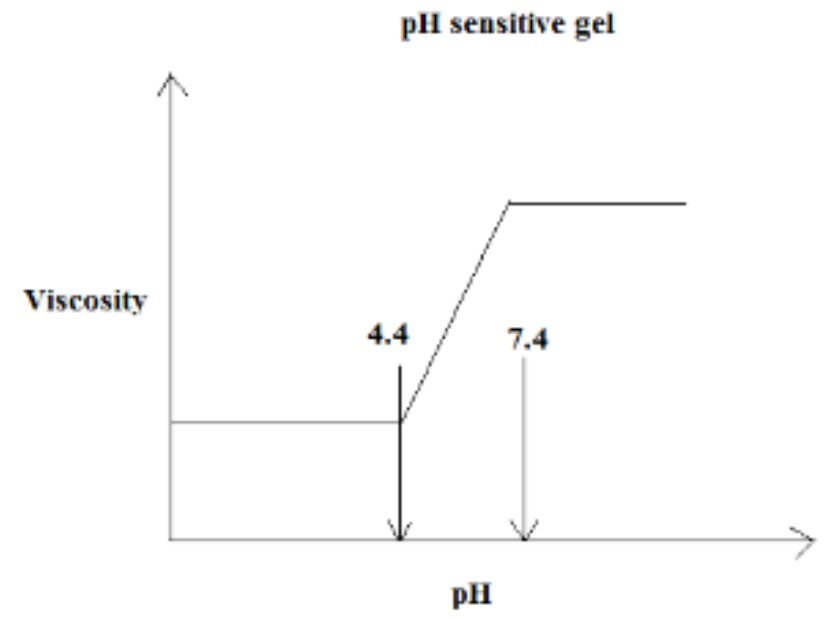

Fig. 3: Graphical representation of $\mathrm{pH}$ sensitive in situ gelling system

\section{Temperature sensitive in situ gelling system}

These are liquid solutions at room temperature $\left(25-27{ }^{\circ} \mathrm{C}\right)$ and undergo gelation when in contact with body fluid $\left(35-37^{\circ} \mathrm{C}\right)$ due to change in temperature. Temperature sensitive gels are three types; positive temperature sensitive gel, negative temperature sensitive gel, thermally reversible gel. Negative temperature sensitivegel has Lower Critical Solution Temperature (LCST), suchgel contracts on heating above LCST25, 26. Positive temperature sensitive gel has an Upper Critical Solution Temperature (UCST) such gel contracts on cooling below UCST.
Examples: Pluronic (Poloxamer), Cellulose derivatives, Polymethacrylates [16]

\section{Mechanism}

The sol-gel phase transition occurs upon increasing temperature is due to three mechanisms: Desolvation of the polymer, increased micellar aggregation and increased entanglement of polymeric network [17]. When temperature increases polymeric chain degraded, leads to the formation of hydrophobic domain and phase transition (liquid to hydrogel) occurred [18]. 

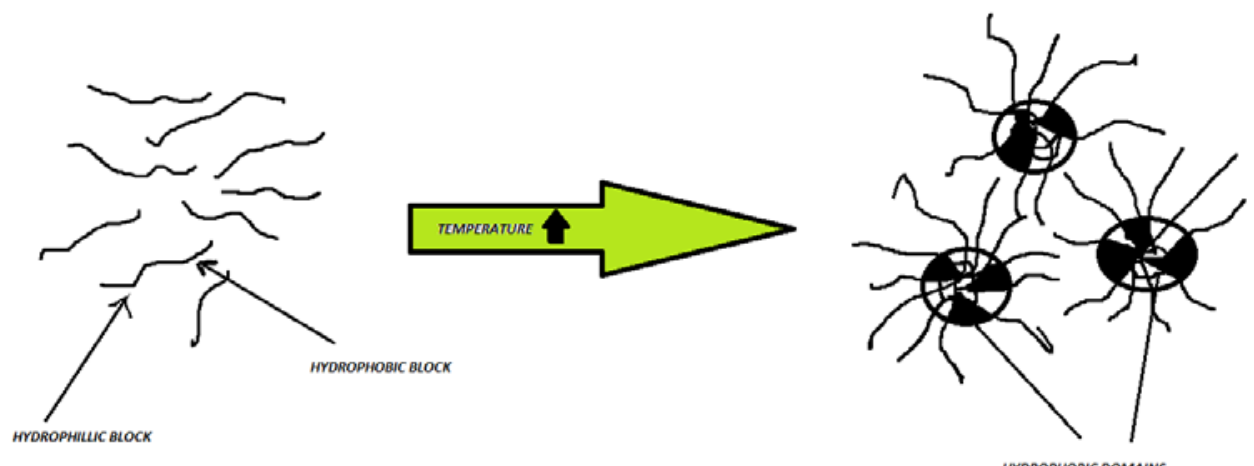

Fig. 4: Mechanism of temperature sensitive in situ gelling system

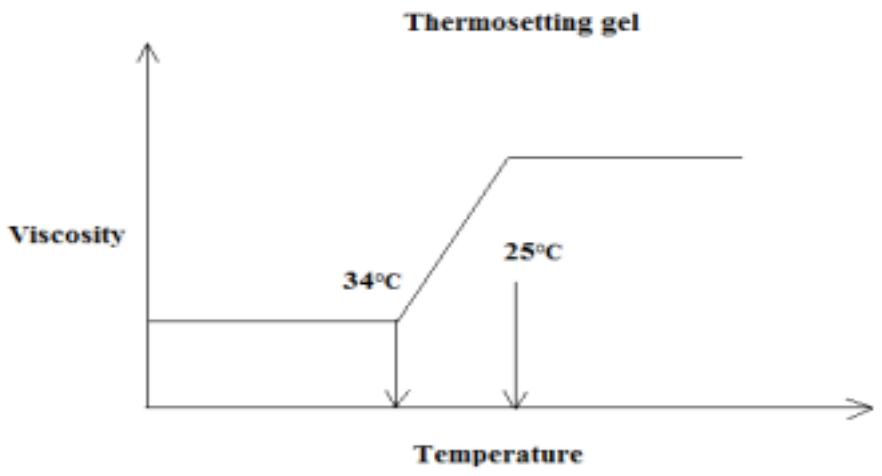

Fig. 4: Graphical representation of temperature sensitive in situ gelling system

\section{Ion sensitive gelling system}

Gelation is triggered by the presence of cations $(\mathrm{Na}+, \mathrm{Mg}++$, $\mathrm{Ca}++)$ in the tear fluid. These can be achieved by polymers like sodium alginate, gellan gum [19]. Gelation is occurred by ionic interaction of polymer and divalent ions of tear fluid. When anionic polymers come in contact with cationic ions, it converts to form gel $[19,20]$.

Examples: Gellan gum (Gelrite R), Sodium Alginate

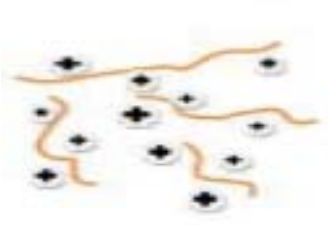

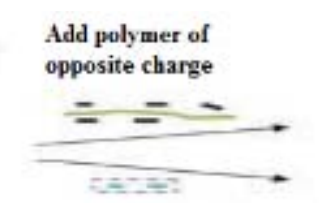

Add small molecule cross-linker of opposite charge

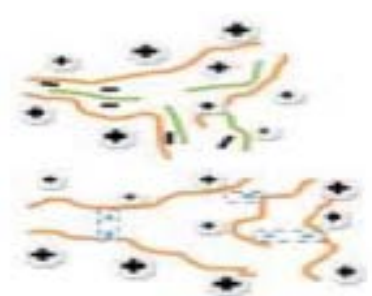

Fig. 5: Mechanism of Ion sensitive in situ gelling system

Electrolyte setting gels

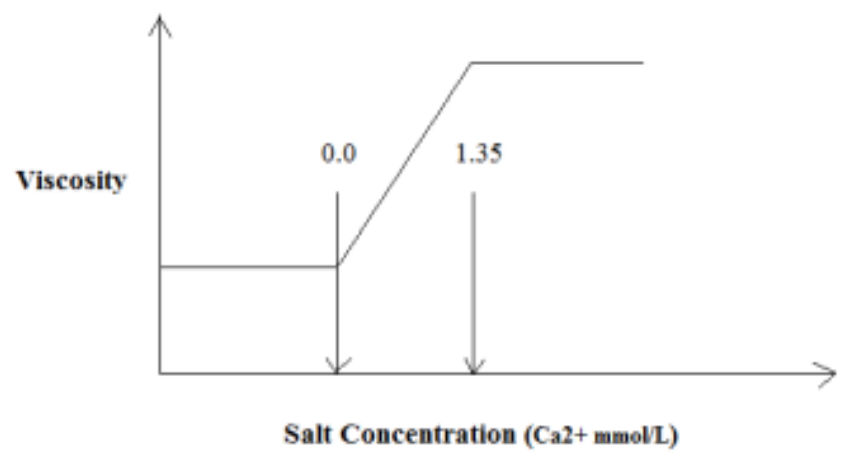

Fig. 6: Graphical representation of ion activated in situ gelling system 


\section{Evaluations of in situ gel system}

Evaluation parameters for in situ gel formulations includes clarity, $\mathrm{pH}$ measurement, gelling capacity, drug content, rheological study, in vitro diffusion study, isotonicity, antibacterial activity, in vivo ocular testing in rabbits and accelerated stability studies. The formulation should have an optimum viscosity that will allow for easy instillation into the eye as a liquid (drops), which would undergo a rapid sol-to-gel transition (triggered by $\mathrm{pH}$, temperature or ion exchange) [21].

\section{Physical parameters}

Physical parameters to be tested for in situ gel solution are clarity, $\mathrm{pH}$, gelling capacity, and drug content estimation.

\section{Gelling capacity}

The gelling capacity of the prepared formulation is determined by placing a drop of the formulation in a vial containing $2.0 \mathrm{ml}$ of freshly prepared simulated tear fluid and visually observe.

\section{Rheological studies}

The viscosity measurements can be calculated using Brookfield viscometer, Cone and Plate viscometer. In-situ gel formulation is placed in sample tube. Formulation should have viscosity of 5-1000 $\mathrm{m}$ Pas, before gelling and after formation of gel should have viscosity from about 50-50,000 $\mathrm{m}$ Pas [22, 23].

\section{In vitro drug release studies}

In vitro release study of in situ gel solution is carried out by using Franz diffusion cell. The best fit model is check for Krosmeyers Peppas and Fickinian diffusion mechanism for their kinetics [24].

\section{Texture analysis}

The consistency, firmness and cohesiveness of in situ gel are assessed by using texture profile analyzer which mainly indicated gel strength and easiness in administration in vivo. Higher values of adhesiveness of gels are needed to maintain an intimate contact with mucus surface.

\section{Isotonicity evaluation}

Isotonicity is important characteristic of the ophthalmic preparations. Isotonicity has to be maintained to prevent tissue damage or irritation of eye. All ophthalmic preparations are subjected to isotonicity testing, since they exhibited good release characteristics and gelling capacity and the requisite viscosity.

\section{Drug-polymer interaction study and thermal analysis}

Interaction study should be performed with Fourier Transform Infra-Red (FTIR) spectroscopy. During gelation process the nature of the interacting forces can be evaluated using the technique by employing $\mathrm{KBr}$ pellet method. Thermo gravimetric Analysis (TGA) can be conducted for in situ forming polymeric system to quantitate the percentage of water in hydrogel. Differential Scanning Calorimetry (DSC) conducted to observe if there are any changes in thermo grams as compared with pure active ingredients used for gelation. [25,26]

\section{Antibacterial activity}

The microbiological growth of bacteria is measured by concentration of antibiotics and this has to be compared with that produced by known concentration of standard preparation of antibiotic.

\section{Ocular irritancy test}

The Draize irritancy test should design for the ocular irritation potential of the ophthalmic product prior to marketing. According to the Draize test, the amount of substance applied to the eye is normally $100 \mu$ placed into the lower cul-de-sac with observation of the various criteria made at a designed required time interval of $1 \mathrm{hr}$, $24 \mathrm{~h}, 48 \mathrm{~h}, 72 \mathrm{~h}$, and 1 week after administration. Three rabbits (male) weighing 1.5 to $2 \mathrm{~kg}$ are used for the study. The sterile formulation is instilled twice a day for a period of $7 \mathrm{~d}$, and a cross-over study is carried out (a $3 \mathrm{~d}$ washing period with saline was carried out before the cross-over study). Rabbits are observed periodically for redness, swelling, watering of the eye [27].

\section{CONCLUSION}

Polymers play a major role in the delivery of drug from its dosage form. Polymeric in situ gelling system provides prolonged release of drug as compared to conventional delivery system. Innumerable natural, synthetic, semi synthetic polymers are developed for controlled release of drug. Use of biodegradable and biocompatible polymers for in situ gel formulation makes acceptable and controlled drug delivery system. Thus sustained and prolonged release of drug, biocompatibility characteristics makes in situ gel dosage form a reliable one.

Development of ophthalmic drug delivery system has proved to be beneficial as compared to the conventional drug delivery system. Likewise it is also challenging enough to establish successful ophthalmic drug delivery systems. However, the persistent attempts towards advancement in the understanding of principles and processes governing ocular drug absorption and disposition have led to the improvements in the efficacy of ophthalmic delivery systems. One such novel approach is development of in-situ ocular gels. Sustained and prolonged release of the drug, good stability and biocompatibility characteristics make the in situ gel dosage forms very reliable. The evaluation of in-situ gels can be carried out based on the parameters like gelling capacity, rheological studies, in vitro drug release studies, drug-polymer interaction study, thermal analysis, antibacterial activity and ocular irritancy test. Use of biodegradable and water soluble polymers for the in situ gel formulations can make them more acceptable and excellent drug delivery systems. In situ activated gel-forming systems seemed to be favoured as they can be administered in drop form and produce appreciably less inconvenience with vision. Moreover, they provide better sustained release properties than drops. This type of dosage forms are used now a days in combat glaucoma, uveitis, dry eye syndrome, sjogren's syndrome, ARMD, trachoma etc.

\section{AUTHORS CONTRIBUTIONS}

All the author have contributed equally

\section{CONFLICT OF INTERESTS}

Declare none

\section{REFERENCES}

1. Gupta A, Manocha N. Formulation and evaluation of in situ ophthalmic drug delivery system. Int J Pharm Bio Arch 2012;3:715-8.

2. Kumar L, Singh RP, Singh SG, Kumar D. In situ gel: a novel system for ocular drug delivery. Int J Pharm Sci Rev Res 2011;9:83-91.

3. Ravikumar PS, Pashte S. In-situ ophthalmic gel forming solution of moxifloxacin hydrochloride for sustained ocular delivery. Int J Phrm Sci Res 2015;34:1192-205.

4. Baranowski PB, Karolewicz B, Gajda M. Ophthalmic drug dosage forms: characterisation and research methods. Sci world J 2014;2:4-6.

5. Nirmal HB, Bakliwal SR. In-situ gel: new trends in controlled and sustained drug delivery system. Int J Phrm Tech Res 2010;2:1398-410.

6. Rathore KS, Nema RK, Ishibashi T, Yokoi N, Born JA, Tiffany MJ, et al. Review on ocular inserts. Int J Pharm Tech Res 2009;1:164-9.

7. Dale SA, Cynthia MB. Ophthalmic preparations. Stimuli Revision Process 2013;39:1-5.

8. Gupta H, Jain S, Mathur R, Mishra P, Mishra AK. Sustained ocular drug delivery from a temperature and $\mathrm{PH}$ triggered novel in-situ gel system. Drug Delivery 2007;14:507-15.

9. Rajoria G, Gupta A. In-situ gelling system: a novel approach for ocular drug delivery. Am J Pharm Tech Res 2012;2:25-53.

10. Rajas NJ, Kavitha K, Gounder T, Mani T. In-situ ophthalmic gels a developing trend. Int J Pharm Sci Rev Res 2011;7:8-14.

11. Nanjundswamy NG, Fatima SD, Sholapur HN. A review on hydrogels and its use in in situ ocular drug delivery. Indian J Novel Drug Delivery 2009;1:11-7. 
12. Mohanambal E, Arun $\mathrm{K}$, Abdul Hasan SA. Formulation and evaluation of pH-triggered in-situ gelling system of levofloxacin. Indian J Pharm Edu Res 2011;45:58-64.

13. Shastri D, Pandya H, Parikh RK, Patel CN. Smart hydrogels in controlled drug delivery. Pharma Times 2006;38:13-8.

14. El-Kamel AH. In vitro and in vivo evaluation of pluronic F 127 based ocular delivery system for timololmaeate. Int J Pharm 2002;241:47-55.

15. Liu Z, Li J, Nie S, Hui-Liu, Ding P, Pan W. Study of alginate/HPMC based in situ gelling ophthalmic delivery system for gatifloxacin. Int J Pharm 2006;315:12-7.

16. Soniya R, Devasani, Asish Dev S. An overview of in situ gelling systems. Pharm Bio Evaluation 2016;3:61-9.

17. Tinu TS, Thomas L, Kumar AB. Polymers used in ophthalmic in situ gelling system. Int J Pharm Sci Rev Res 2013;20:176-83.

18. Kumar L, Singh RP, Singh SG, Kumar D. In situ gel: a novel system for ocular drug delivery. Int J Pharm Sci Rev Res 2011;9:83-91

19. Talat F, Sadhana RS, Azmat MS, Nityanand Z, Syed A Formulation development and evaluation of in situ ophthalmic gel of sodium cromoglycate. Der Pharm Sin 2013;4:109-18.
20. Agarwal KM, Namdev A, Gupta AK. In situ gel formation for ocular drug delivery system: an overview. Asian J Bio Pharm Sci 2011;1:1-7.

21. Nittur JR, Kunchu K, Theetha G, Tamizh M. Review on in situ ophthalmic gels: a developing trend. Int J Pharma Sci Rev Res 2011;7:8-14.

22. Shin SC, Kim JY, Oh IJ. Mucoadhesive and physicochemical characterization of carbopol-poloxamer gels containing triamcinolone acetonide. Drug Dev Ind Pharm 2000;26:307-12.

23. Rajoia G, Gupta A. In situ gelling system: a novel approach for ocular drug delivery. Am J Pharm Tech Res 2012;2:25-53.

24. Vengurlekar P, Singh A, Rathod S. Microspheric in situ gel for ocular drug delivery system of bromfenac sodium. Int J Pharma Sci Res 2014;5:179-85.

25. Gambhire S, Bhalerao K, Singh S. Review on in situ hydrogel: different approaches to ocular drug delivery. Int J Pharm Pharm Sci 2013;5:27-36

26. Madan $\mathrm{M}$, Bajaj A. In situ forming polymeric drug delivery systems. Indian J Pharm Sci 2009;1:242-3.

27. Rathore KS, In situ gelling ophthalmic drug delivery system: an overview. Int J Pharm Pharm Sci 2015;2:1-22. 